\title{
ORGANIC LIVESTOCK FARMING AND PRECONDITIONS FOR ITS DEVELOPMENT IN SOUTH EAST BULGARIA
}

\author{
K. Stoyanov* \\ Department of Industry Business and Entrepreneurship, Faculty of Economics, \\ Trakia University, Stara Zagora, Bulgaria
}

\begin{abstract}
The goal of the article is to show the importance and growing economical interest for organic livestock farming and to underline its potential for the region of South East Bulgaria. For this purpose will be made a review of existing theoretical framework that will settle the scope of organic livestock farming for the purpose of this research. A general overview of the Dynamic market growth for organic products and its perspectives will be drawn along with existing rules and EU regulations especially in the field of eco and organic certification. Some main conclusions will be made following the existing official statistical data and trends. A general conclusion on organic livestock farming profitability compared to conventional farming systems will be made to approve the competitive advantage that it could provide to the region of Southeast Bulgaria.
\end{abstract}

Key words: organic products, EU Eco regulation, organic producers distribution, profitability

\section{INTRODUCTION}

Organic livestock farms are faced with a major problem - producing goods that can be successfully certified while maintaining sufficiently high levels of economic efficiency, allowing them to profit from the agriculture as a business. Often these two contradictory responsibilities such as production practices that meet the requirements for organic production even thou they tend to have lower results than the conventional production methods. This determines the distribution of relatively higher production costs on relatively small volumes of output and hence high cost. To lower production costs bio proceedings are subject to public support. In our country there is a discrepancy between the objectives and the results of that support. Despite the social cost, the consumption of organic products is relatively small, due the bulk of these products being sold on international markets.

The complex nature of the target set in the project's research problem involves the use of an integrated approach in the selection of indicators. For the realization of the target in

\footnotetext{
*Correspondence to: Konstantin Stoyanov, $P h D$,

Room 385, Faculty of Economics, Trakia

University, Students Campus, 6000 Stara Zagora,

Bulgaria, Tel: +35942699432,

stoyanov.konstantin@gmail.com
}

this proposal it is necessary to combine a variety of research methods and techniques leading to the drafting of a comprehensive methodology for assessing the production potential of bio-products. So the set framework of the study, suggests combining different marketing approaches, technical and production techniques and economic indicators to identify the processes leading to "current picture" of the market for organic products in the domestic market and give possible solutions to improve implementation on the Bulgarian market.

For the purpose of the article a review of the existing terminology on organic livestock breeding should be introduced as the European Union is very strict on the subject of organic farming and it has developed a proper community based legislation and procedures due to the importance of the food sector and consumer rights in all member states. Additionally, the metadata used for some of the analysis on the article is taken from Eurostat and the methodology of collecting it is based on the existing terminological framework within the European Union.

According to different sources on European Union level, Organic farming is a way of agricultural production that uses organic production methods and places the greatest 
emphasis on environmental and wildlife conservation and animal welfare considerations. In the context of European Union statistics, agriculture is considered organic if it complies with Regulation (EC) No 834/2007 of 28 June 2007 on organic production and labelling of organic products.

Organic operator is any natural or legal person who produces, prepares, imports, exports or deals with organic products. Organic producer is any natural or legal person who operates an agricultural holding involved in producing, packaging and labelling his own organic products. Organic processor is any natural or legal person who preserves and/or processes organic agricultural produce (including slaughter and butchering of livestock). Packaging and labelling of organic products is also considered to be processing. Mixed organic operator is an operator involved in more than one of the activities, e.g. a producer who is also processing (not only his own products).

\section{CERTIFICATION OF ORGANIC LIVESTOCK FARIMNG PRODUCTS}

There are different certification bodies and agencies across different European countries. Some of them differ in terms of requirements that need to be met by organic farming producers. The frequency of the controlling process is also different from on to the other. Thus we will refer to the existing legislation and procedure on EU level which guarantees the common interest of European citizens in terms of food protection and consumer rights. The EU requires an equally strict control system with checks carried out at every stage of the organic chain. Every operator (farmer, processor, trader, importer or exporter) is checked at least once a year, or more often on the basis of risk assessment.

The reference document is the Council Regulation (EC) No 834/2007 of 28 June 2007 on organic production and labelling of organic products. It is further backed up by another
STOYANOV K.

legislative instrument, namely the Commission Regulation (EC) No 889/2008 of 5 September 2008 laying down detailed rules for the implementation of Council Regulation (EC) No $834 / 2007$ on organic production and labelling of organic products with regard to organic production, labelling and control.

Some of the most important regulations in terms of organic livestock farming concern the breeding and feeding procedures in livestock organic farms. Thus, Organic livestock must be born and raised on organic farms.

For breeding purposes, non-organically raised animals may be brought onto a holding under specific conditions. Such animals and their products may be deemed organic after compliance with the conversion period referred to in Article 17(1) (c). Particular attention should be paid to housing conditions, husbandry practices and stocking densities to ensure that the developmental, physiological and ethological needs of animals are met. Moreover, the choice of breeds should take account of their capacity to adapt to local conditions.

The feed for livestock should primarily be obtained in the farm where the animals are kept or from farms in the same region. Farmers have to provide $100 \%$ organic feed to their cattle in order to market their products as organic or to use the EU logo.

\section{ORGANIC LIVESTOCK FARMING OPPORTUNITIES}

Data shows that permanent pasture represents the biggest share of the organic area $(58 \%)$, followed by cereals $(20 \%)$ and permanent crops $(15 \%)$. Sheep $(42 \%)$ and cattle $(34 \%)$ are the most important types of organic animal production at European level, after poultry. However, other types of animal production should be mentioned in the EU28, such as pigs, which registered $9 \%$, and goats, which were at $7 \%$ of organic livestock in European Union in 2015.

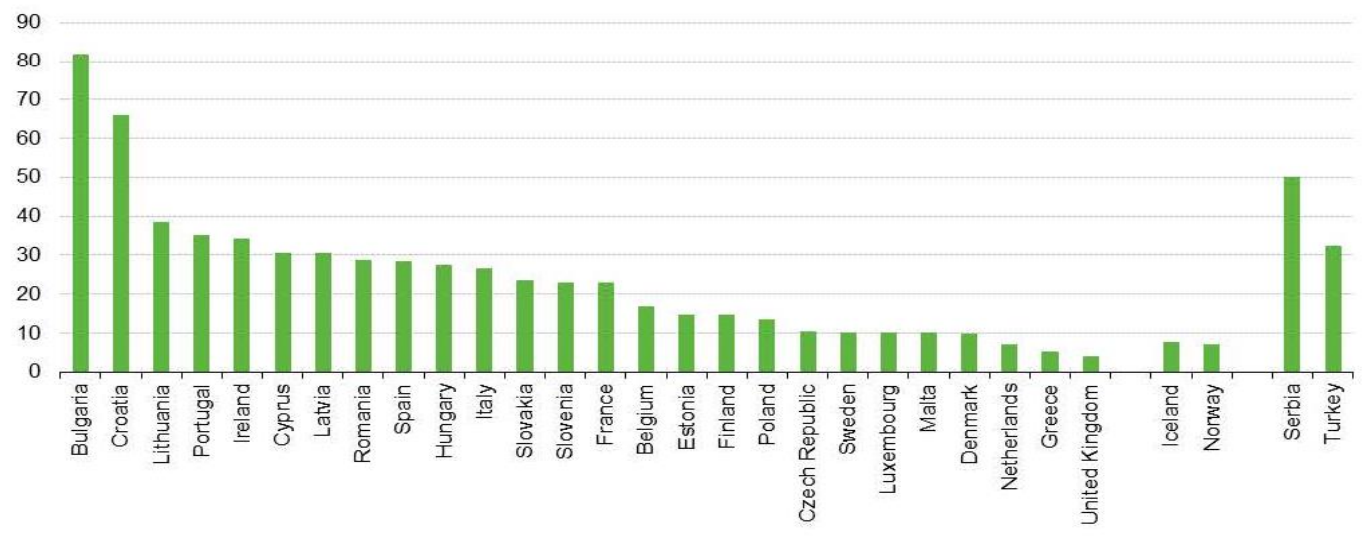

Note: No data available for Germany and Austria

Source: Eurostat

Figure 1. Rate of agricultural land in conversion (\% from all currently organic certified) 
According to the official data Bulgaria is in first place among all European countries in terms of land in conversion into organic agricultural land. A clarification should be made that the figure represents the rise of organic agricultural land in percentage compared to the existing organic agricultural land and not the size of the actual organic agricultural land area.

As shown before the existing of organic agricultural products is one of the more important requirements for organic livestock farming, this is the main reason that this data is interesting to the current research.

Table 1. Number of animals breed organically*

\begin{tabular}{|l|l|l|l|l|l|l|l|l|l|}
\hline & $\mathbf{2 0 0 6}$ & $\mathbf{2 0 0 7}$ & $\mathbf{2 0 0 8}$ & $\mathbf{2 0 0 9}$ & $\mathbf{2 0 1 0}$ & $\mathbf{2 0 1 1}$ & $\mathbf{2 0 1 2}$ & $\mathbf{2 0 1 3}$ & $\mathbf{2 0 1 4}$ \\
\hline Cattle & 329 & 395 & 470 & 272 & 364 & 976 & 1173 & 1311 & 1622 \\
\hline Sheep & 1054 & 1690 & 2471 & 5831 & 6698 & 6648 & 9175 & 7894 & 9029 \\
\hline Caprine & 131 & 1058 & 1624 & 2732 & 2773 & 3397 & 2831 & 3235 & 4142 \\
\hline Bee colonies & 33981 & 35747 & 44861 & 41089 & 46429 & 58855 & 85346 & 117360 & 106676 \\
\hline
\end{tabular}

Source: MAF, According to data from the annual reports of the controlling persons of organic production

The increasing role of the sector in Bulgaria recorded based on the growth in the number of animal units grown organically is easily traceable in the table above. The number of animals in the country that have undergone a period of transition at the end of 2014, from which organic production has derived amounted to 1344 cattle, 7250 sheep and 3201 goats and 89,553 bee colonies. Organic production collected during the year was as follows: raw cow's milk - 1123.89 tons, raw sheep milk - 379.77 tons, raw goat milk -
982.54 tons, honey - $\quad 1 \quad 516.77$ tons. (Agricultural Report 2015, MAF)

Looking back at the preconditions for organic livestock farming, it is important for organic producers to have organic farms in the neighbouring area. Thus, most of the grazing animals need large open-air areas of organic food. Generally, those type of lands refer to pastures according to the classification of the EU legislation.

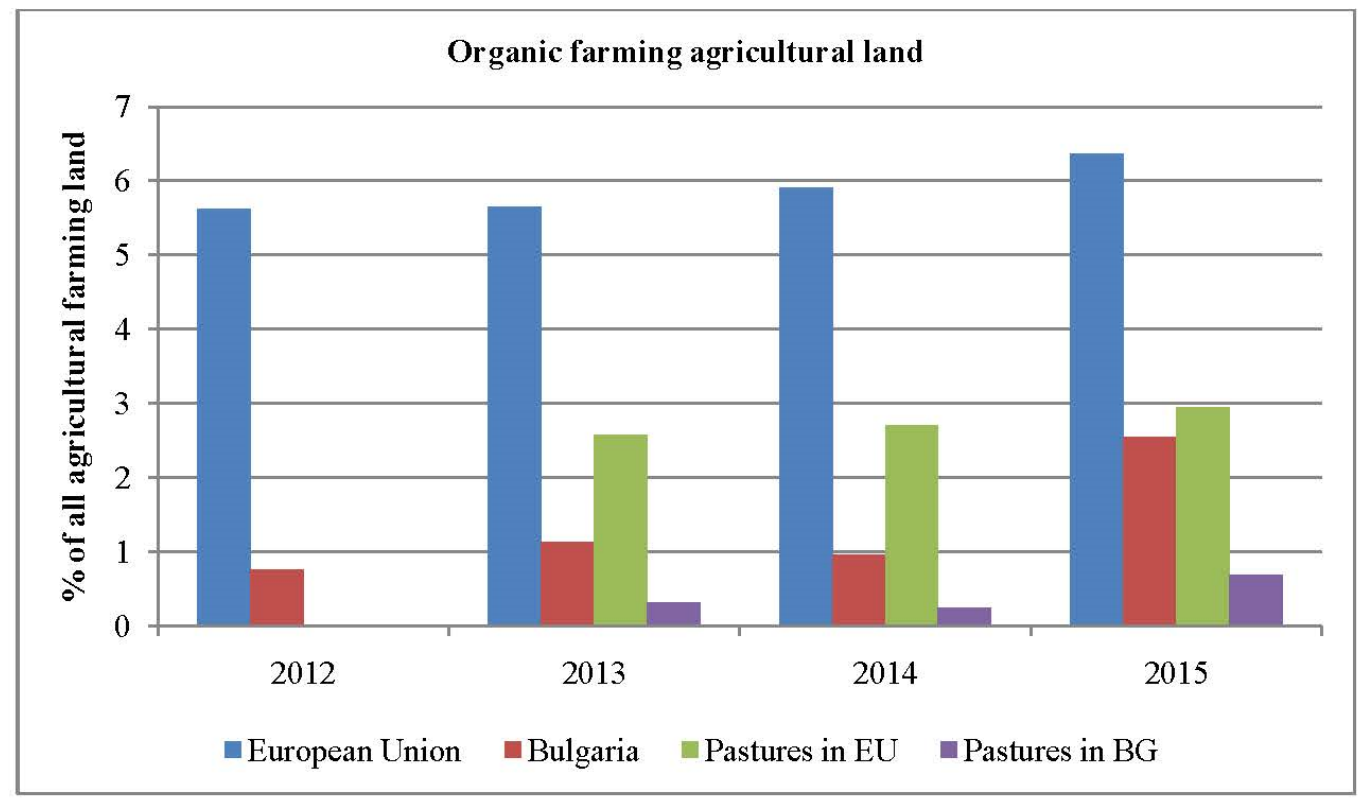

Source: Interpretation of metadata from Eurostat

Figure 2. Relative weight of Pastures in EU and Bulgaria compared to organic and common agricultural land

It is further interesting to see that organic pastures are rapidly growing in size compared to all agricultural farming land. They are following the general trend in Bulgaria and are constantly representing around $27 \%$ of the size of organic agricultural land during the span of 2013-2015. 


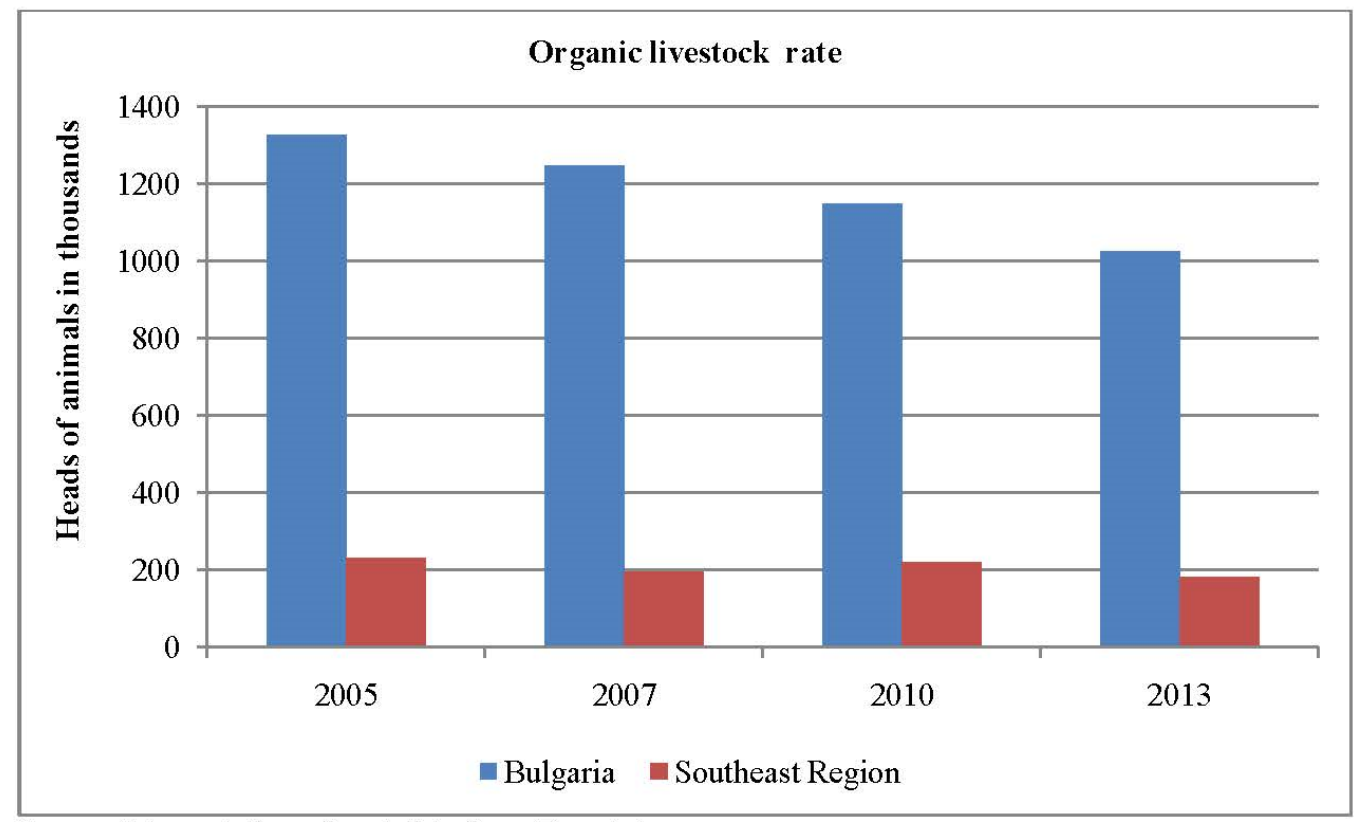

Source: Interpretation of metadata from Eurostat

Figure 3. Organic livestock in Bulgaria

When looking at the potential of the organic livestock farming in Southeast region of Bulgaria, there is a very limited amount of officially collected data. Nevertheless, using available information provided by Eurostat, some general conclusions might be drawn.

In terms of heads of animals, surprisingly there is a downward trend in Bulgaria. No conclusions on its origins could be drawn from the available sources. As far as the Southeast region is concerned, it somehow stays around 200000 organic heads of animals for the period 2005-2013 with some fluctuation of over or under 20000 . This represents 16 to $19 \%$ of all organic livestock farming in the country during that span.

Looking back at the data, there is enough information to presume that organic livestock farming has established itself as such in the agricultural sector of Southeast Bulgaria. This means that there are some existing traditions, knowledge and experience on regional level that might be used to scale up the impact of organic livestock farming in the region.

\section{CONCLUSIONS}

Three are the main conclusions that may be drawn from the analysis so far.

Firstly, Bulgaria ranks first in the EU by percentage of agricultural land in conversion in 2015. This is a necessary precondition for organic agriculture and its production is a requirement for organic livestock farming and breeding. Thus the potential of organic livestock farming which has a greater added value could be developed in the recent years to come.

Secondly, organic livestock farming in Bulgaria is generally below the EU's normal values. Nevertheless all data shows that the country is rapidly catching up with its lagging behind. Specifically, the percentage of agricultural land in conversion is factor that needs to be taken into consideration. At the same time, the demand of organic products, both agricultural and animal, is consistently rising not only in EU, but in most of the economically strong countries which is a precondition for the sector to be in the rise in the recent future.

Thirdly, in the Southeast region there is a trend of smooth growth of the main indicators of organic livestock breeding. The region is largely seen and has been traditionally developing into one of the most important agricultural and farming regions in Bulgaria. The preconditions of knowledge and experience are in place to ease the process of developing the Southeast region into one of the leading in the sector of organic livestock farming.

Although the organic farming is not as profitable as the conventional farming systems, it has an interesting economic potential due to its added value and constantly growing demand worldwide, presenting an important opportunity for the sector's upward trend. 


\section{ACKNOWLEDGMENTS}

This research was established as a part of Project № M05/4"Production capacity and local consumption of organic products from livestock breeding in Southeast Region" funded by National Scientific research fund and the Ministry of science and education of Republic of Bulgaria.

\section{REFERENCES}

1. Eurostat, Organic farming statistics, October 2016

2. European Commission, The competitive position of the European food and drink industry, February 2016

3. Council Regulation (EC) No 834/2007 of 28 June 2007 on organic production and labelling of organic products and repealing Regulation (EEC) No 2092/91

4. Commission Regulation (EC) No 889/2008 of 5 September 2008 laying down detailed rules for the implementation of Council Regulation (EC) No 834/2007 on organic production and labelling of organic products with regard to organic production, labelling and control

5. DG Agriculture and Rural Development, Facts and figures on organic agriculture in the European Union, December 2016

6. Escribano, A., Organic livestock Farming - Challenges, Perspectives, and Strategies to Increase Its Contribution to the Agrifood System's Sustainability - A Review, "Organic Farming - A Promising Way of Food Production", book edited by Petr Konvalina, ISBN 978-953-51-2256-2, CC BY 3.0 license, 2016

7. Meredith, S., Willer, H., "Organic in Europe. Prospects and developments 2016", ISBN: 978-3-03736-313-3, IFOAM EU and FiBL, 2016 
